\title{
BMJ Open Understanding the characteristics of recurrent visits to the emergency department by paediatric patients: a retrospective observational study conducted at three tertiary hospitals in Korea
}

\author{
Byung-Soo Kim, Jung-Youn Kim, Sung-Hyuk Choi, Young-Hoon Yoon
}

To cite: Kim B-S, Kim J-Y, Choi S-H, et al. Understanding the characteristics of recurrent visits to the emergency department by paediatric patients: a retrospective observational study conducted at three tertiary hospitals in Korea. BMJ Open 2018;8:e018208. doi:10.1136/ bmjopen-2017-018208

- Prepublication history for this paper is available online To view these files, please visit the journal online (http://dx.doi org/10.1136/bmjopen-2017018208).

Received 14 June 2017 Revised 19 January 2018 Accepted 25 January 2018

\section{Check for updates}

\section{Department of Emergency} Medicine, College of Medicine, KoreaUniversity, Seoul, Republic of Korea

Correspondence to Dr Jung-Youn Kim; yellowwizard@hanmail.net

\section{ABSTRACT}

Objectives The number of paediatric patients visiting the emergency department (ED) continues to rise. In South Korea, approximately $25 \%$ of the patients who visit the ED are paediatric patients. In the USA, about $20 \%$ of the paediatric population were found to have visited the $E D$ in the past year. A recent study demonstrated that $4.5 \%-8 \%$ of patients account for $25 \%$ of all ED visits. Therefore, the aim of this study was to identify the characteristics of recurrent visits.

Methods Design: retrospective observational study. Setting: this study examined and analysed medical record data involving three tertiary EDs. Participants: a total of 46 237 ED visits by patients $<16$ years during 1-year period. Main outcome measures: data collected included the number of recurrent ED patients, frequency of recurrent visits, age, sex, insurance status, period until recurrent visit (days), main diagnosis and ED discharge results. Results Excluding patients with multiple visits, the total number of paediatric patients who fit the study criteria was 33765 . Among these patients, $23384(69.2 \%)$ had no recurrent ED visits in the subsequent year after their first visit. A total of $15849(46.8 \%)$ patients were toddlers (between age 1 and 4 years). In the patient group without a recurrent visit, fever was the most common diagnosis. Conclusions Our study reviewed medical records to inspect the characteristics of patients who return to care. Higher recurrent visit frequency was associated with using the 119 rescue centre service, having a medical condition, with younger age and a higher rate of hospitalisation. Analysis of the factors associated with frequent $E D$ visits will help to improve care for paediatric patients who visit the ED.

\section{INTRODUCTION}

Paediatric patients' use of the emergency department (ED) is continuously increasing each year. ${ }^{1}$ In South Korea, despite the continuous decrease in the infant population due to the low birth rate, the number of paediatric patients visiting EDs has been growing each
Strengths and limitations of this study

- This is the first study to identify the characteristics of the emergency department recurrent visits in children in Korea, considering the unique characteristics of the local population.

- Our findings indicated that younger age, using emergency medical services, medical illness and higher rate of hospitalisation were associated with a higher recurrent visit frequency.

- Understanding the characteristics of patients is very important for physician who need to adjust human and facility resources of the emergency department.

- The study included sample size that was limited to three hospitals.

- Analysis of this retrospective study included only variables available in the hospital database that were routinely collected.

year. ${ }^{2}$ In the country, approximately $25 \%$ of the patients visiting the ED are paediatric patients. ${ }^{3}$ In the USA, about 80000 paediatric patients visit the ED on a daily basis and $20 \%$ of the paediatric population have been visiting the ED every year. ${ }^{45}$

Recurrent use of the emergency medical service is defined as repeated visits to an ED by a specific person during a certain period of the year. ${ }^{67}$ According to a recent study, as few as $4.5 \%-8 \%$ patients account for $25 \%$ of all ED visits. ${ }^{8}$ However, studies involving paediatric patients and repeated visits to the ED are limited. The ED can be a starting point for paediatric patients with an acute internal medical condition or surgical condition. ${ }^{9}{ }^{10}$ Paediatric patient visits to the ED may continue to increase and when the ED capacity is exceeded, first aid may be delayed in serious cases and waiting time may increase. 
This leads to undermining medical service quality and aggravating a situation of an already overcrowded and inefficient ED. ${ }^{11}{ }^{12}$ Paediatric patients' recurrent visits to the $\mathrm{ED}$ can be considered as a factor influencing the quality of care provided in the ED. Identification and management of frequent ED visits will be necessary in the future. Moreover, many paediatric emergency patients, unlike adults, visit for non-emergent problems. ${ }^{13-17}$ Understanding the characteristics of recurrent visits of paediatric patients will facilitate the implementation of clinical interventions, the reduction of the frequency of recurrent visits, and thus, mitigation of factors associated with overcrowded EDs can be accomplished. Therefore, this study aimed to identify the number and the characteristics of patients who visited the ED frequently. The primary outcome was to identify the number and the rate of recurrent visiting paediatric patients in the ED, and the secondary outcome was to identify the characteristics of these patients and the common diagnosis by frequency of visits.

\section{MATERIALS AND METHODS}

This retrospective study reviewed the medical records of patients younger than 16 years who had visited an ED from 1 January 2012 to 31 December 2012. Data from the medical records were analysed for the subsequent year as well (1 January 2013-31 December 2013) (figure 1). The medical institutions involved in this study were three university hospitals in Gangnam, Gangbuk (both in Seoul), and Gyeonggi. Excluding cases of return visits, cases of recurrent visits were identified during the investigation period (initial visit-2012). Accordingly, 33765 patients were identified as having used the ED and were included in the study analysis.

A 'recurrent visit' was defined as a patient visiting an ED more than once over the study period. The purpose of this study was to identify the characteristics of paediatric patients who frequently used the ED. Therefore, the study excluded any cases of revisiting the ED for the same illness within 72 hours, which was defined as a 'return visit'. ${ }^{4}$ Patients' age, sex, insurance type, visit frequency, time from initial visit until revisit (days), main diagnosis, ED discharge result and length of stay in ED were examined. Based on patients' age, a recurrent visit ratio was calculated. To investigate associated characteristics and factors, patients were classified according to the number of recurrent visits as follows: zero recurrent visits, one recurrent visit, two recurrent visits, three recurrent visits and four or more recurrent visits.

This research design was chosen because it attempts to explore possible causative relationships between recurrent ED visits and other variables (number of recurrent ED patients, frequency of recurrent visits, age, sex, insurance status, time until recurrent visit, main diagnosis and ED discharge results). Because randomization was not possible in a retrospective study, the control procedure

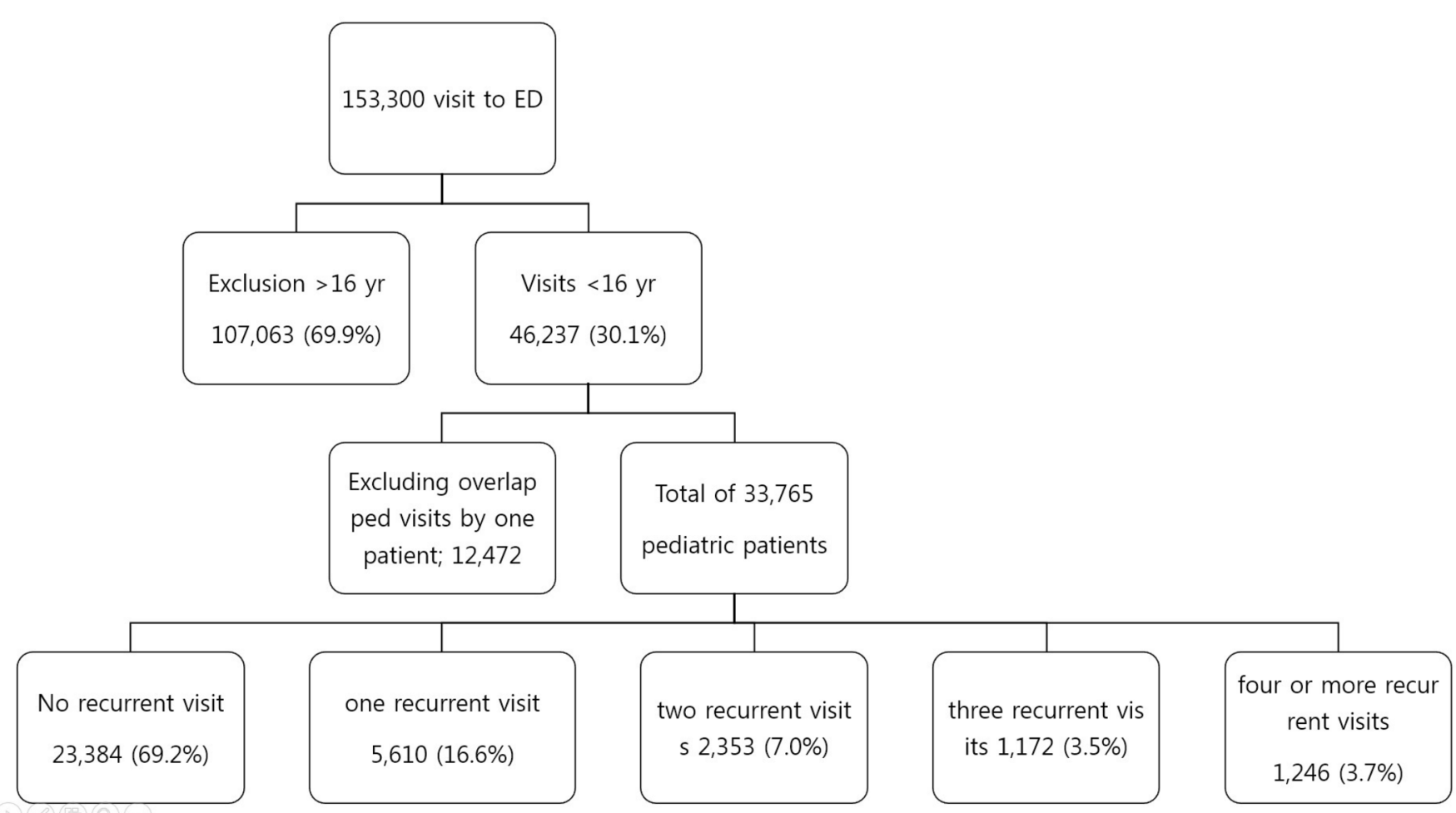

Figure 1 Flow chart of sample selection. During 1 year, a total of 153300 visits in ED were recorded. Among them, there were 46237 visits of patients under 16 years. Excluding repeated visits by one patient, 33765 paediatric patients have used the ED. These patients were divided into groups according to the number of visits during the following year after the initial visit to the ED. ED, emergency department. 


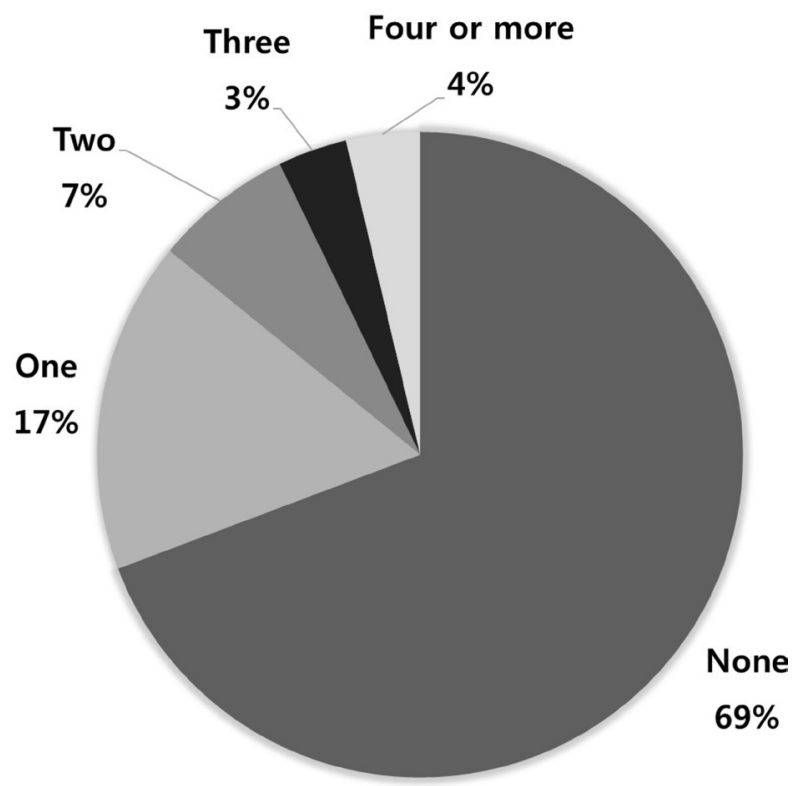

PERCENTAGE OF PATIENT GROUP BY VISIT NUMBER

Figure 2 Comparison of the percentage between patient groups categorised according to their number of visits. $31 \%$ of the patients used the emergency department more than once during the following year after their first visit.

of comparing groups (recurrent visit number) based on collected demographic data was adopted. To account for seasonal variation, we performed our study in a period of one calendar year.

The Strengthening the Reporting of Observational Studies in Epidemiology Statement was used to guide the reporting of the study. ${ }^{18}$

Statistical analysis was performed using SPSS software (V.20.0; IBM SPSS) using frequency analysis. Null hypotheses of no difference were rejected if $\mathrm{P}$ values were less than 0.05 . A $\mathrm{P}<0.05$ was considered statistically significant. Each measured value was expressed as mean \pm SD. Comparisons between groups were divided per the number of visits. Significant differences were determined using a Student's t-test and one-way analysis of variance as statistical methods. For nominal variables, percentage gaps were compared using Fischer's exact test and $\chi^{2}$ test in line with the number of cases in each group.

\section{RESULTS}

The three hospital EDs were visited 153300 times by patients during the investigation year (from 1 January 2012 to 31 December 2012), including 46237 (30.1\%) times by paediatric patients aged younger than 16 years. Excluding multiple number of visits by one patient, a total of 33765 paediatric patients used the EDs during 2012 and were included in this study (figure 1). The number of recurrent visits of these patients was identified during the following year after the first visit. A total of $23384(69.2 \%)$ paediatric patients visited the ED once, whereas $5610(16.6 \%)$ visited twice (one recurrent visit), $2353(7.0 \%)$ visited three times (two recurrent visits),
$1172(3.5 \%)$ visited four times (three recurrent visits) and $1246(3.7 \%)$ visited five or more times (four or more recurrent visits). Therefore, $31 \%$ of the patients used the ED more than once during the following year after the first visit (figure 2).

Of the 33765 paediatric patients, 19155 (56.7\%) were boys and $14610(43.3 \%)$ were girls. The recurrent visit rate for boys was $1.64 \pm 1.3$ times higher than that of girls $(\mathrm{P}<0.01)$. In terms of age-specific distribution, 6438 (19.1\%) were infants (12 months old or younger), 15849 (46.8\%) were toddlers (1-4 years old), 6719 (19.9\%) were children between the ages of 5 and 9 years, 3927 $(11.7 \%)$ were children aged between 10 and 14 years and $832(2.5 \%)$ were 15 years old. Of these age groups, the infant group showed the highest recurrent visit number with an average of $1.78 \pm 1.5$ times visit $(\mathrm{P}<0.01)$. Patient insurance types were allocated as follows: $32349(95.8 \%)$ had medical insurance, $476(1.4 \%)$ received medical aid, $393(1.2 \%)$ were not insured, 505 (1.5\%) had automobile insurance and $42(0.1 \%)$ had international insurance. The medical-aid patient group showed the highest recurrent visit number $(1.70 \pm 1.7(\mathrm{P}<0.01))$ (table 1$)$. The recurrent visit graph of each age group indicates that older age is associated with a lower number of recurrent visits. However, this decreasing trend was not apparent at ages 11 and 12 years, when the rate slightly increased (figure 3).

A total of $23384(69.2 \%)$ patients were found to have no recurrent visits; of these, $1168(5.21 \%)$ arrived at the hospital via a 119 rescue centre vehicle, 5568 (23.8\%) had injuries and $17169(73.4 \%)$ had medical conditions. A total of 12986 (58.0\%) were boys. Of those, 2597 $(11.1 \%)$ were found to have the ED discharge as the result of hospitalisation. For the group of patients with

\begin{tabular}{|c|c|c|}
\hline Characteristic & n (\%) & $\begin{array}{l}\text { Recurrent visit } \\
\text { number } \pm S D\end{array}$ \\
\hline \multicolumn{3}{|l|}{ Patient sex } \\
\hline Male & 19155 (56.7) & $1.64 \pm 1.3(P<0.01)$ \\
\hline Female & 14610 (43.3) & $1.56 \pm 1.3$ \\
\hline \multicolumn{3}{|l|}{ Patient age, years } \\
\hline Infant & 6438 (19.1) & $1.78 \pm 1.5(P<0.01)$ \\
\hline $1-4$ & $15849(46.8)$ & $1.70 \pm 1.4$ \\
\hline $5-9$ & 6719 (19.9) & $1.42 \pm 1.0$ \\
\hline $10-14$ & 3927 (11.7) & $1.34 \pm 0.9$ \\
\hline 15 & $832(2.5)$ & $1.25 \pm 0.7$ \\
\hline \multicolumn{3}{|l|}{ Medical insurance } \\
\hline Public & 32349 (95.8) & $1.61 \pm 1.3(P<0.01)$ \\
\hline Self-pay & $393(1.2)$ & $1.51 \pm 1.2$ \\
\hline Medical care & $476(1.4)$ & $1.70 \pm 1.7$ \\
\hline Commercial (car) & 505 (1.5) & $1.28 \pm 0.7$ \\
\hline International & $42(0.1)$ & $1.10 \pm 0.4$ \\
\hline
\end{tabular}




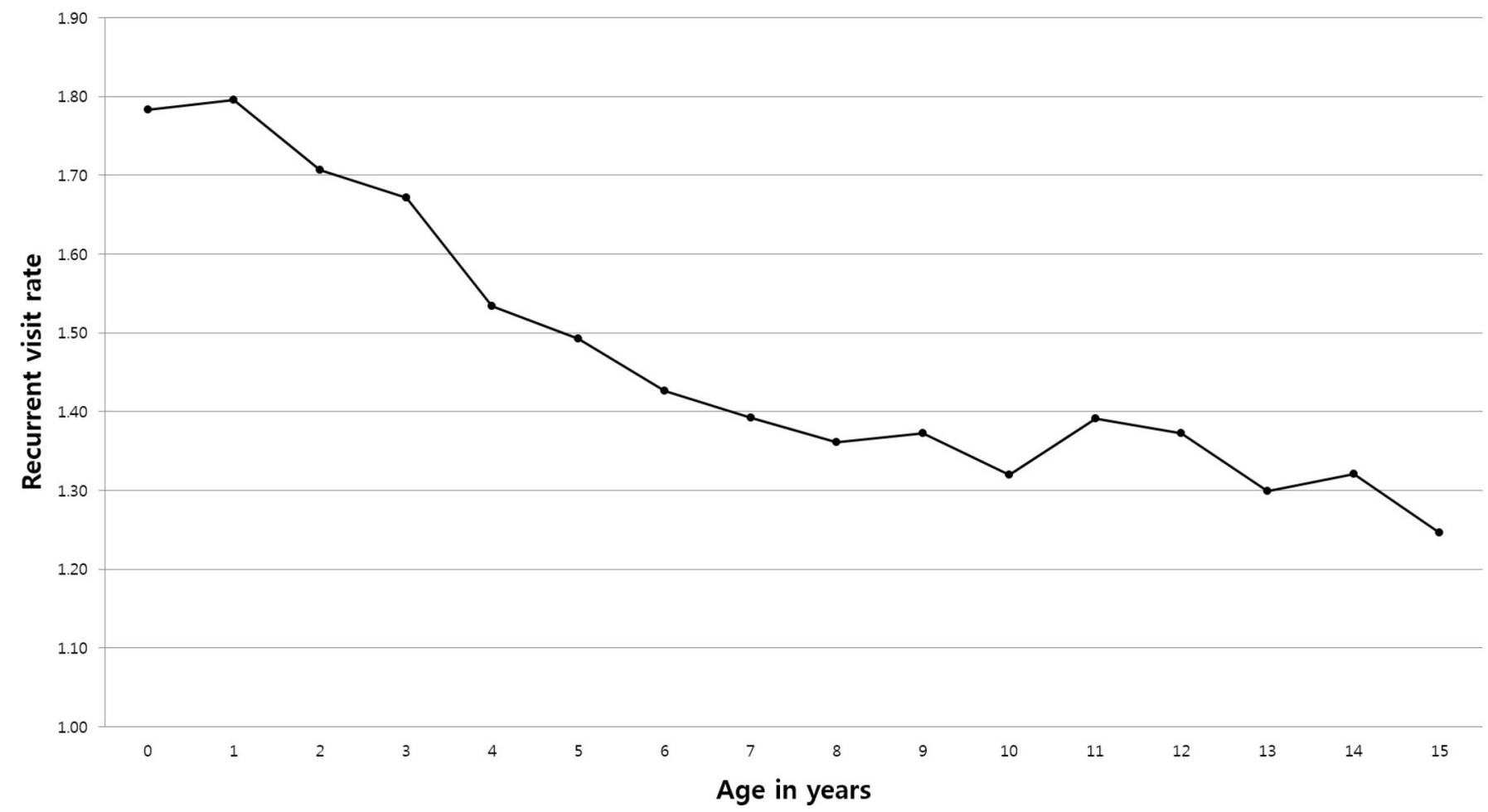

Figure 3 Average visit rate according to age (in years). This graph demonstrates the average number of visits according to age. One-year-old children show the highest number of recurrent visits. Age is inversely correlated with the number of recurrent visits.

one recurrent ED visit, the average time between the initial visit to the next visit was $114.6 \pm 111.0$ days, and for the group of patients with four or more recurrent visits, the interval was $69.0 \pm 82.5$ days. Among patients arriving at the hospital with a 119 rescue vehicle, $5.21 \%$ were patients without a recurrent visit, and $6.7 \%$ were patients with four or more recurrent visits. There was no significant difference in the proportion of patients with chronic disease, regardless of the number of recurrent visits. The length of ED stay of patients with four or more recurrent visits $(147.8 \pm 169.8 \mathrm{~min})$ was longer than that of patients with no recurrent visits $(138.6 \pm 160.1 \mathrm{~min})$; however, there was no significant statistical difference (table 2).

The top five illnesses/injuries associated with the ED visits were identified for each recurrent-visit frequency group. In the patient group without a recurrent visit, fever was the primary diagnosis followed by gastroenteritis and colitis of unspecified origin. A similar pattern was found in the one recurrent-visit group. In the four or more recurrent-visits group, gastroenteritis and colitis of unspecified origin was more frequently observed than fever. In the two or three recurrent-visits groups, the frequency of superficial injury was not in the top five diagnoses. In the four of more recurrent-visit group, the incidence of febrile convulsions was third in the list (table 3 ).

\section{DISCUSSION}

Our retrospective study examined the medical records of paediatric patients in South Korea and identified characteristics associated with recurrent ED visits. Of all patients visiting EDs in this country, 25.4\% were younger than 15 years in 1996, according to Park and Dh. ${ }^{19}$ Since then, although epidemiological data are lacking, ED visits seem to be continuously increasing. ${ }^{2}$ An increase in the number of ED visits of paediatric patients has been observed recently, and recurrent visits may account for this increase. Therefore, this study examined the characteristics of paediatric patients who repeatedly visited EDs.

During the year of this study investigation, 31\% of the patients used the ED more than once during the following year after the first visit. In a previous study of hospital revisits by adult patients, $16.8 \%$ were defined as recurrent-visit patients. ${ }^{20}$ In comparison, a larger proportion of paediatric patients presented recurrently to the ED. ${ }^{20}$ There are many different reasons that may account for the high frequency of paediatric visits to $\mathrm{ED}$, which are distinct from those regarding adult patients. In adult patients, chronic health issues are associated with the frequent use of the ED. ${ }^{4}$ Generally, younger children are more susceptible to infectious diseases. ${ }^{21} 22$ Therefore, it is assumed that age is inversely correlated with the number of visits to the ED. Our study revealed that fever was a major cause of ED visits and a higher frequency of recurrent ED visits was associated with younger age; therefore, infectious diseases and the age group seem to be important characteristics.

We found that older age was associated with a lower frequency of recurrent visits, consistent with a study by 


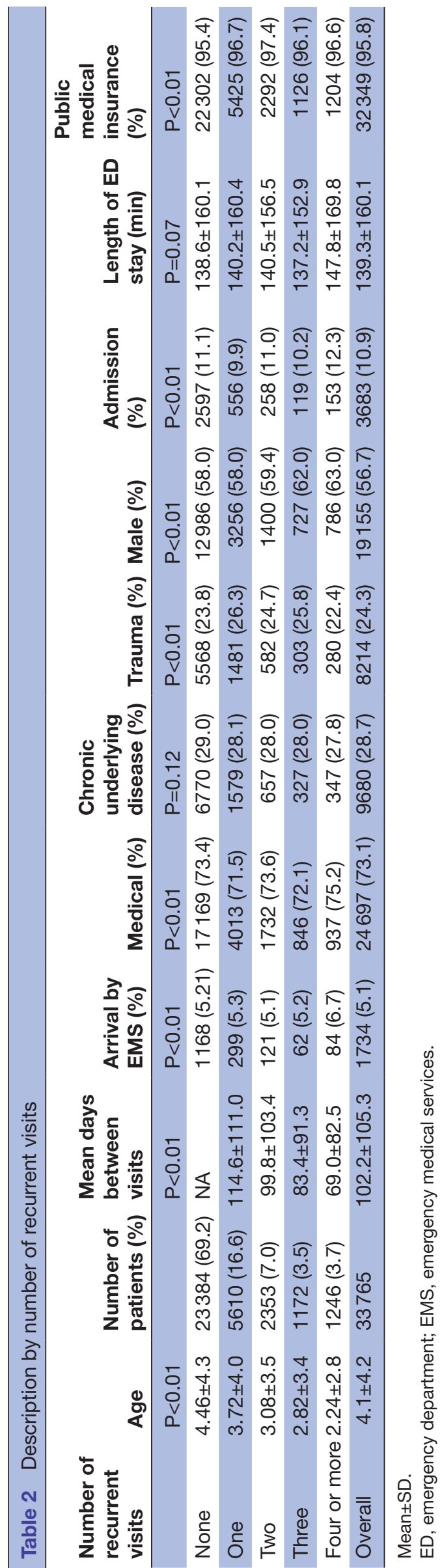

the Pediatric Emergency Care Applied Research Network (PECARN).${ }^{4}$ In the PECARN study, the highest recurrent visit frequency was found in patients 5 years old or less; of these, 3-year-old children showed the highest rate of recurrent visits. Older age was associated with a lower rate of recurrent visits. Given that fever is the top reason for recurrent visits, this finding indicated that the higher frequency of recurrent ED visits at a younger age was due to fever. This indicates that most parents and guardians visited the ED in response to fever in their child. ${ }^{22} 23$

In a US study, ${ }^{4}$ patients who had public insurance showed the highest number of recurrent visits to the ED. This finding is in contrast to another study, which found that patients with private medical care (medical aid) insurance have visited ED more often. ${ }^{713}$ Our result showed no difference between the number of recurrent visits and insurance type. These contradictory findings are possibly due to the differences between the US and South Korean insurance policies. In Korea, most patients are insured under the nationwide medical insurance, and those with medical aid still receive support for their medical costs from the national government. Therefore, there is no financial burden associated with ED visits. ${ }^{7824-26}$

Patients with four or more recurrent visits appeared to show higher rates of using the 119 rescue services $(6.7 \%)$ than other groups. In South Korea, 119 services for ED visits are operated by the government and are free of charge for the patients. It seems that the use of an ambulance once facilitated the decision for the next use. The ratio of trauma (22.4\%) was lower in the group of patients with four or more visits than other groups, while the ratio of medical conditions $(75.2 \%)$ was higher. In our study, the number of recurrent visits for patients with chronic medical diseases did not differ significantly compared with other patients. This is in contrast to previous studies ${ }^{46}$ which showed that chronic medical diseases were more frequently diagnosed in patients who visited more than four times. According to Neuman et al, ${ }^{26}$ the type of hospital may have affected the distribution of chronic patients, and generalisation is challenging due to the nature of the hospital, because in nursing hospitals or child specialisation hospitals, more patients may have chronic conditions.

The hospitalisation rate was also far higher in the group of patients with four or more recurrent ED visits. Neuman et $a t^{26}$ reported that patients who visited more than four times had fewer hospitalisations, which is in contrast to our study. According to a study by Seguin et $a l,{ }^{13}$ the number of frequent users was higher in young children and neonates showed a $38 \%$ hospitalisation rate. In the study of Alpern $e t a l,{ }^{4}$ the admission rate of the group that visited more than four times was the highest, similar to our study. In our study, the use of emergency medical services (EMS), the existence of a medical condition and a higher rate of hospitalisation were higher in the group of patients that visited ED more than four times. Therefore, frequent visits seem to be related to these three variables. 
Table 3 Five most frequent diagnoses according to the number of recurrent visits

\begin{tabular}{|c|c|c|c|c|c|}
\hline Rank & None $(n, \%) n=23384$ & One $(n, \%) n=11220$ & Two (n, \%) n=7059 & Three $(n, \%) n=4688$ & $\begin{array}{l}\text { Four or more }(n, \%) \\
n=8149\end{array}$ \\
\hline 1 & $\begin{array}{l}\text { Fever, } \\
\text { unspecified (2337, } \\
10.4)\end{array}$ & $\begin{array}{l}\text { Fever, unspecified (622, } \\
11.0)\end{array}$ & $\begin{array}{l}\text { Fever, } \\
\text { unspecified }(240,10.1)\end{array}$ & $\begin{array}{l}\text { Gastroenteritis and } \\
\text { colitis of unspecified } \\
\text { origin }(123,10.4)\end{array}$ & $\begin{array}{l}\text { Fever, } \\
\text { unspecified (137, } \\
10.9)\end{array}$ \\
\hline 2 & $\begin{array}{l}\text { Gastroenteritis and } \\
\text { colitis of unspecified } \\
\text { origin }(2154,9.6)\end{array}$ & $\begin{array}{l}\text { Gastroenteritis and colitis } \\
\text { of unspecified origin ( } 523 \text {, } \\
9.3 \text { ) }\end{array}$ & $\begin{array}{l}\text { Gastroenteritis and } \\
\text { colitis of unspecified } \\
\text { origin }(220,9.3)\end{array}$ & $\begin{array}{l}\text { Fever, } \\
\text { unspecified }(118,10.0)\end{array}$ & $\begin{array}{l}\text { Gastroenteritis and } \\
\text { colitis of unspecified } \\
\text { origin }(118,9.4)\end{array}$ \\
\hline 4 & $\begin{array}{l}\text { Acute pharyngitis, } \\
\text { unspecified }(785,3.5)\end{array}$ & $\begin{array}{l}\text { Concussion, unspecified, } \\
\text { without open intracranial } \\
\text { wound }(196,3.4)\end{array}$ & $\begin{array}{l}\text { Acute bronchitis, } \\
\text { unspecified }(94,3.9)\end{array}$ & $\begin{array}{l}\text { Acute pharyngitis, } \\
\text { unspecified }(54,4.6)\end{array}$ & $\begin{array}{l}\text { Acute bronchitis, } \\
\text { unspecified }(64,5.1)\end{array}$ \\
\hline 5 & $\begin{array}{l}\text { Superficial injury } \\
\text { of face NOS, other } \\
\text { injury }(742,3.3)\end{array}$ & $\begin{array}{l}\text { Superficial injury of face } \\
\text { NOS, other injury (194, } \\
3.4)\end{array}$ & $\begin{array}{l}\text { Influenza due to } \\
\text { specific identified } \\
\text { influenza virus }(91,3.8)\end{array}$ & $\begin{array}{l}\text { Influenza due to } \\
\text { specific identified } \\
\text { influenza virus }(45,3.8)\end{array}$ & $\begin{array}{l}\text { Acute pharyngitis, } \\
\text { unspecified }(58,4.6)\end{array}$ \\
\hline
\end{tabular}

NOS, not otherwise specified.

The most common diagnosis in paediatric patients was fever. Data from overseas studies showed that asthma was the major reason for recurrent visits. ${ }^{4}$ In our study, no major differences were observed between patient groups and disease groups regarding ED visits. Patients with minor diseases, such as seasonal influenza or common cold, who present to ED frequently can be systematically managed for the efficient use of the ED resources.

The characteristics of patients visiting the ED varied depending on age, region and socioeconomic conditions. Each hospital ED is different and unique. Our study focused on the characteristics of paediatric patients with recurrent ED visits, which has thus far been rarely studied. Although our study investigated the ED use at three medical institutions through the retrospective examination of medical records, it is limited because it does not represent the characteristics of all EDs throughout South Korea. ${ }^{27}$ Moreover, most medical treatment in this country relies on national medical insurance. Some people have additional private insurance, which has been identified as an important factor facilitating additional ED use. However, private insurance could not be identified in medical records and was not considered in this study analysis, which consists another limitation of our study.

Our study has some limitations. First, missing data may exist similar to other retrospective chart reviews. Second, because the diagnosis itself is limited to the ED, it may change during treatment. In addition, our study did not include information about the patient's use of resources in the ED (imaging, laboratory findings, etc).

This study examined the characteristics of paediatric patients with recurrent ED visits. Future studies should be implemented to examine similar characteristics in hospitals nationwide, identify patients at risk of recurrent $\mathrm{ED}$ visit, consider structural improvements in EDs and provide the basic data for improving the quality of EMS.

\section{CONCLUSIONS}

This study reviewed medical records to investigate the characteristics of paediatric patients' recurrent visit. Younger age was correlated with a higher frequency of recurrent visits. The major reasons for recurrent visits were fever and infectious diseases. In the group of patients with the highest frequency of recurrent visits, associated characteristics were the usage of 119 rescue services, the presence of internal medical condition(s) and the higher rate of hospitalisation.

Contributors J-YK designed the study, wrote the manuscript and performed statistical analyses. B-SK collected data and contributed to the interpretation of the results. S-HC and Y-HY conceived the study and edited the manuscript. J-YK is responsible for the manuscript as a whole.

Funding This research received no specific grant from any funding agency in the public, commercial or not-for-profit sectors.

Competing interests None declared.

Patient consent Not required.

Ethics approval The approval of the Institutional Review Board (IRB) was obtained from the Korea University Guro Hospital (IRB No. Kugh15277).

Provenance and peer review Not commissioned; externally peer reviewed. Data sharing statement There are no additional data available.

Open Access This is an Open Access article distributed in accordance with the Creative Commons Attribution Non Commercial (CC BY-NC 4.0) license, which permits others to distribute, remix, adapt, build upon this work non-commercially, and license their derivative works on different terms, provided the original work is properly cited and the use is non-commercial. See: http://creativecommons.org/ licenses/by-nc/4.0/

C Article author(s) (or their employer(s) unless otherwise stated in the text of the article) 2018. All rights reserved. No commercial use is permitted unless otherwise expressly granted.

\section{REFERENCES}

1. Pitts SR, Niska RW, Xu J, et al. National hospital ambulatory medical care survey: 2006 emergency department summary. Natl Health Stat Report 2008;7:1-38. 
2. Kim DK, Kwak YH, Lee SJ, et al. A national survey of current practice patterns and preparedness of pediatric emergency care in Korea. $J$ Kor Soc Emerg Med 2012;23:126-31.

3. Tak KC, Son MS, Ko YG, et al. A study on time consuming of arrival and emergency treatment of the patients admitted to the emergency room. J Kor Soc Emerg Med 1993;4:78-93.

4. Alpern ER, Clark AE, Alessandrini EA, et al. Recurrent and highfrequency use of the emergency department by pediatric patients. Acad Emerg Med 2014;21:365-73.

5. Health UDoNational Center for Health Statistics. Health, United States, 2010, 2010.

6. Locker TE, Baston S, Mason SM, et al. Defining frequent use of an urban emergency department. Emerg Med J 2007;24:398-401.

7. Hunt KA, Weber EJ, Showstack JA, et al. Characteristics of frequent users of emergency departments. Ann Emerg Med 2006;48:1-8.

8. LaCalle E, Rabin E. Frequent users of emergency departments: the myths, the data, and the policy implications. Ann Emerg Med 2010;56:42-8.

9. Yamamoto LG, Zimmerman KR, Butts RJ, et al. Characteristics of frequent pediatric emergency department users. Pediatr Emerg Care 1995:11:340-6.

10. Pitts SR, Carrier ER, Rich EC, et al. Where Americans get acute care: increasingly, it's not at their doctor's office. Health Aff 2010;29:1620-9.

11. Carroll $A E$, Frakt $A B$. New evidence supports, challenges, and informs the ambitions of health reform. JAMA 2013;309:2600-1.

12. Mathison DJ, Chamberlain JM, Cowan NM, et al. Primary care spatial density and nonurgent emergency department utilization: a new methodology for evaluating access to care. Acad Pediatr 2013;13:278-85.

13. Seguin J, Osmanlliu E, Zhang $X$, et al. Frequent users of the pediatric emergency department. CJEM 2017:1-8.

14. Brousseau DC, Bergholte J, Gorelick MH. The effect of prior interactions with a primary care provider on nonurgent pediatric emergency department use. Arch Pediatr Adolesc Med 2004;158:78-82.

15. American Academy of Pediatrics Committee on Pediatric Emergency Medicine. Overcrowding crisis in our nation's emergency departments: is our safety net unraveling? Pediatrics 2004:114:878-88.
16. Doobinin KA, Heidt-Davis PE, Gross TK, et al. Nonurgent pediatric emergency department visits: Care-seeking behavior and parental knowledge of insurance. Pediatr Emerg Care 2003;19:10-14.

17. Halfon N, Newacheck PW, Wood DL, et al. Routine emergency department use for sick care by children in the United States. Pediatrics 1996;98:28-34.

18. von Elm E, Altman DG, Egger M, et al. The Strengthening the Reporting of Observational Studies in Epidemiology (STROBE) Statement: guidelines for reporting observational studies. Int J Surg 2014;12:1495-9.

19. Park JH, Dh W. Clinical analysis of the pediatric death patients visiting emergency center. J Kor Soc Emerg Med 1998;9:445-51.

20. Doran KM, Raven MC, Rosenheck RA. What drives frequent emergency department use in an integrated health system? National data from the Veterans Health Administration. Ann Emerg Med 2013;62:151-9.

21. Hoot NR, Aronsky D. Systematic review of emergency department crowding: causes, effects, and solutions. Ann Emerg Med 2008;52:126-36.

22. Jacobstein CR, Alessandrini EA, Lavelle JM, et al. Unscheduled revisits to a pediatric emergency department: risk factors for children with fever or infection-related complaints. Pediatr Emerg Care 2005;21:816-21.

23. Lasser KE, Kronman AC, Cabral H, et al. Emergency department use by primary care patients at a safety-net hospital. Arch Intern Med 2012;172:278-80.

24. Newton MF, Keirns CC, Cunningham R, et al. Uninsured adults presenting to US emergency departments: assumptions vs data JAMA 2008;300:1914-24.

25. Sandoval E, Smith S, Walter J, et al. A comparison of frequent and infrequent visitors to an urban emergency department. J Emerg Med 2010;38:115-21.

26. Neuman MI, Alpern ER, Hall M, et al. Characteristics of recurrent utilization in pediatric emergency departments. Pediatrics 2014;134:e1025-e1031.

27. Tzimenatos L, Kim E, Kuppermann N. The pediatric emergency care applied research network: a history of multicenter collaboration in the United States. Clin Exp Emerg Med 2014;1:78-86. 